\title{
Inflammasome activation in airway epithelial cells after multi-walled carbon nanotube exposure mediates a profibrotic response in lung fibroblasts
}

Salik Hussain ${ }^{1 *}$, Stacey Sangtian ${ }^{1}$, Shamika M Anderson ${ }^{1}$, Ryan J Snyder ${ }^{1}$, Jamie D Marshburn ${ }^{1}$, Annette B Rice ${ }^{1}$, James C Bonner ${ }^{2}$ and Stavros Garantziotis ${ }^{1}$

\begin{abstract}
Background: In vivo studies have demonstrated the ability of multi-walled carbon nanotubes (MWCNT) to induce airway remodeling, a key feature of chronic respiratory diseases like asthma and chronic obstructive pulmonary disease. However, the mechanism leading to remodeling is poorly understood. Particularly, there is limited insight about the role of airway epithelial injury in these changes.

Objectives: We investigated the mechanism of MWCNT-induced primary human bronchial epithelial (HBE) cell injury and its contribution in inducing a profibrotic response.

Methods: Primary HBE cells were exposed to thoroughly characterized MWCNTs $(1.5-24 \mu \mathrm{g} / \mathrm{mL}$ equivalent to 0.37-6.0 $\mathrm{\mu g} / \mathrm{cm}^{2}$ ) and MRC-5 human lung fibroblasts were exposed to 1:4 diluted conditioned medium from these cells. Flow cytometry, ELISA, immunostainings/immunoblots and PCR analyses were employed to study cellular mechanisms.

Results: MWCNT induced NLRP3 inflammasome dependent pyroptosis in HBE cells in a time- and dose-dependent manner. Cell death and cytokine production were significantly reduced by antioxidants, siRNA to NLRP3, a caspase-1 inhibitor (z-WEHD-FMK) or a cathepsin B inhibitor (CA-074Me). Conditioned medium from MWCNT-treated HBE cells induced significant increase in mRNA expression of pro-fibrotic markers (TIMP-1, Tenascin-C, Procollagen 1, and Osteopontin) in human lung fibroblasts, without a concomitant change in expression of TGF-beta. Induction of pro-fibrotic markers was significantly reduced when IL-1 $\beta$, IL-18 and IL-8 neutralizing antibodies were added to the conditioned medium or when conditioned medium from NLRP3 siRNA transfected HBE cells was used.
\end{abstract}

Conclusions: Taken together these results demonstrate induction of a NLRP3 inflammasome dependent but TGF-beta independent pro-fibrotic response after MWCNT exposure.

Keywords: Multi-walled carbon nanotubes, Nanotoxicity, Fibrosis, Pyroptosis, NLRP3 inflammasome, Human bronchial epithelia

\footnotetext{
* Correspondence: salik.hussain@nih.gov

${ }^{1}$ Clinical Research Unit, National Institute of Environmental Health Sciences (NIEHS)/National Institute of Health (NIH), Research Triangle Park, Durham, NC, USA

Full list of author information is available at the end of the article
} 


\section{Background}

Multi-walled carbon nanotubes (MWCNT) exhibit unique electrical, mechanical, thermal and optic properties, which make them the material of choice for a variety of industrial and consumer product applications. Apart from their conventional utilizations in electronics, composite materials and optics, more recent applications of MWCNT include biomedical engineering, biosensors, drug delivery and gene therapy [1-5]. Given their tremendous potential, it is expected that their applications will continue to grow over the coming years [6]. However, some of the properties which make MWCNTs a material of choice from an engineering aspect (e.g. high tensile strength, high aspect ratio and biopersistence) can also lead to potential toxicity in biological systems [7-12].

At present there is no definitive proof of any human disease due to occupational or environmental exposure to MWCNTs. However, a large body of literature show potential toxic effects in rodents including acute lung inflammation, granuloma formation, epithelial-mesenchymal transition and fibrosis [8,13-17]. Moreover, studies have shown that MWCNTs can translocate from the lungs to the pleura where they cause injury to the mesothelial lining and therefore may cause pleural disease [16,18-21]. An excellent review about the pulmonary toxicity of MWCNT can be found elsewhere [22]. These findings raise concerns about the safety of MWCNTs and warrant further indepth mechanistic analyses to ensure the safety of workers and consumers. Indeed, recent estimates indicate that more than 6 million workers will be involved with nanotechnology by 2020 , one third of whom will reside in the US [23].

Airway remodeling, including increased deposition of extracellular matrix proteins (ECM) plays significant role in the development of symptoms associated with lung function decline in asthma and COPD [24,25]. In lungs more than $10 \%$ of the total ECM is deposited/degraded each day and fibrosis is actually a disturbed balance in favour of its accumulation either due to excessive production or impaired degradation mechanisms [26]. MWCNT induce airway remodeling and fibrosis in rodent models after respiratory exposures $[13,15,16]$. However, the mechanisms of such effects remain poorly elucidated. Some in vitro studies have postulated the role of Transforming Growth Factor-beta (TGF- $\beta$ ) production in the induction of profibrotic response after MWCNT exposures [8,13]. Still others, using cell lines, postulated the role of epithelialmesenchymal transformation (EMT) in airway fibrosis $[17,27]$. These studies mainly focussed on the role of lung macrophages as key mediators in airway fibrosis in rodent models and did not address the injury to airway epithelia as a contributor to these responses. Using a relevant translational model, we explore the mechanistic pathway of primary human epithelial injury and its contribution in airway remodeling after MWCNT exposures. We report here that MWCNT induce pyroptosis (caspase-1-dependent inflammatory cell death) in primary human bronchial epithelial cells. Furthermore, we demonstrate a novel pro-fibrotic mechanism after MWCNT exposures of primary human bronchial epithelial (HBE) cells, which involves nucleotidebinding oligomerization domain (NOD)-like receptor protein 3 (NLRP3) inflammasome activation in HBE cells, inducing Tenascin-C (TN-C), Osteopontin (OPN), Tissue Inhibitor of Metalloprotease-1 (TIMP-1) and Procollagen-1 (PC-1) expression, and proliferation in fibroblasts. Moreover, we demonstrate that this process occurs without denovo TGF- $\beta$ expression and can be effectively modulated by siRNA inhibition of epithelial NLRP3 activation.

\section{Results}

Characterization of nanomaterials and their suspensions

Detailed physico-chemical characterization of MWCNTs was performed before cell culture testing. Data provided by the manufacturer were verified by an independent source and have been reported previously [18]. Briefly, the ICPAES measurements by the independent source showed $99 \%$ elemental carbon, $0.34 \% \mathrm{Ni}$ and $0.03 \% \mathrm{La}$ and $0.7 \% \mathrm{O}_{2}$ (Figure 1). These nanotubes have $10-30 \mathrm{~nm}$ average external diameters, $0.5-40 \mu \mathrm{m}$ average length and $109.29 \mathrm{~m}^{2} / \mathrm{g}$ BET surface area. High resolution TEM and SEM images of MWCNT dry powder is given in Figure 1. MWCNT were suspended in cell culture medium $(24 \mu \mathrm{g} / \mathrm{mL})$ and suspensions were analyzed for hydrodynamic diameter and zeta potentials using DLS technique. DLS revealed that MWCNT form aggregates of $129 \pm 45 \mathrm{~nm}$ size (Additional file 1). Carbon Black (CB) NPs and Min-u-Sil showed $95 \pm$ $10 \mathrm{~nm}$ and $363 \pm 64 \mathrm{~nm}$ hydrodynamic diameters respectively. Zeta potential analyses revealed $-13 \pm 2 \mathrm{mV},-12 \pm$ $3 \mathrm{mV}$ and $-8 \pm 5 \mathrm{mV}$ values for MWCNT, CB and Min-USil respectively. MWCNT and CB samples were tested free of bacterial endotoxin contamination $(<0.3 \mathrm{EU} / \mathrm{mL})$ by endpoint chromogenic limulus amebocyte assay (LAL assay).

\section{MWCNTs enter HBE cells and cause ultra-structural damage}

MWCNTs were taken up by primary HBE cells and were found either in vesicles or free inside the cytoplasm (Additional file 2). In most instances MWCNT clumps/ bundles were seen inside vesicles (Additional file $2 \mathrm{~B}$ and C), however, in some cases we found single nanotubes in contact with the cell membrane or in vesicular membranes, which appeared to be piercing through the membrane (Additional file 2D).

\section{MWCNT induce NLRP3 inflammasome dependent pyroptosis}

MWCNT exposure at 12 and $24 \mu \mathrm{g} / \mathrm{mL}$ induced significant cell death after 24 hours of exposure (flow 


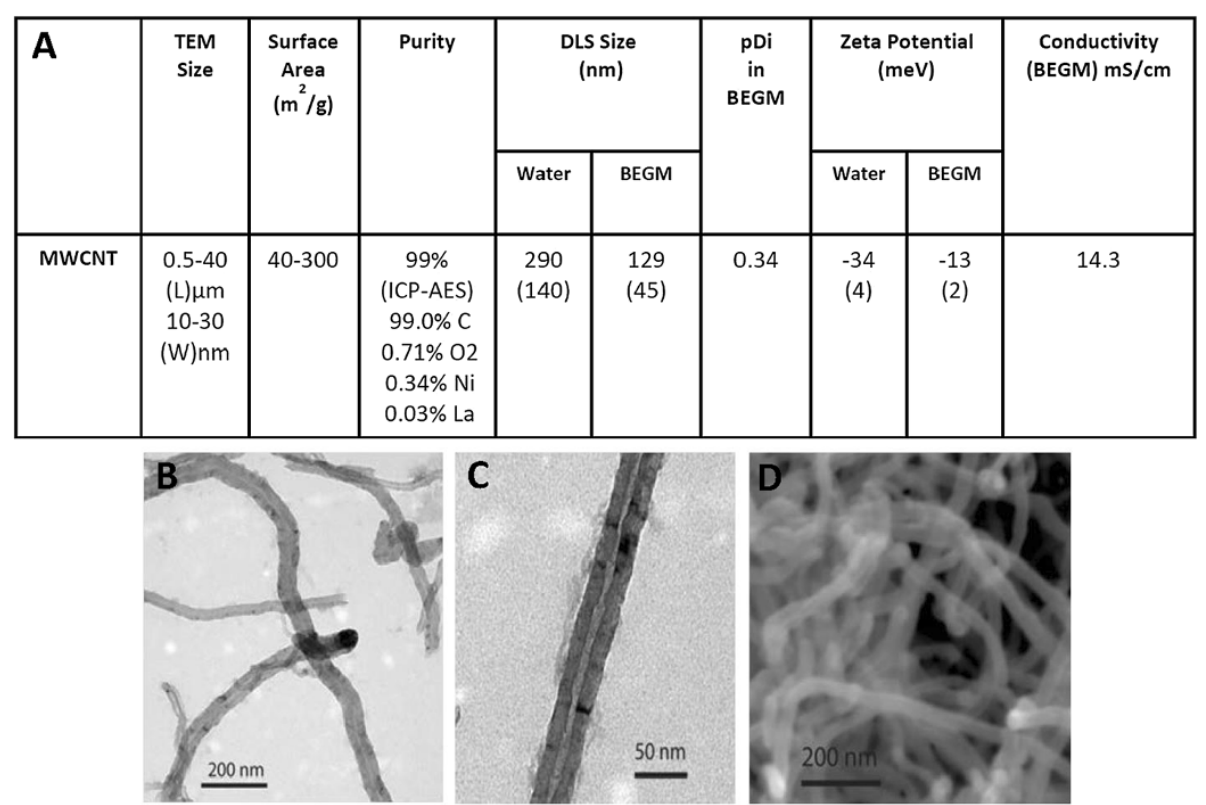

Figure 1 Physico-chemical characteristics of MWCNT powder and suspensions. A) summary of characteristics in a table format. pDi refer to polydispersity index B, C) TEM and D) SEM analyses of MWCNT powder.

cytometery data) (Figure 2A). No cell death was observed after CB NP exposure (shape control/negative control) while Min-U-Sil (particulate positive control) did cause significant toxicity. Hydrogen peroxide $\left(\mathrm{H}_{2} \mathrm{O}_{2}\right)$ was used as positive control for oxidative stress. A kinetic analysis (4, 18, 24 and 48 hours exposure) revealed significant cell death induction starting at 18 hours with $24 \mu \mathrm{g} / \mathrm{mL}$ MWCNT exposure and at 24 hours with $12 \mu \mathrm{g} / \mathrm{ml}$ MWCNT exposure with the response being persistent up to 48 hours (Additional file 3). Cell death estimation was verified using three independent methods i.e. flow cytometry (propidium iodide staining), LDH assay and trypan blue exclusion cell counts). All three assays for cytotoxicity estimation demonstrated comparable results (Additional file 4A-B). Furthermore, MWCNT exposure caused a significant increase in caspase-1 positive cells (Figure 2B). These results were also confirmed using western blot analysis for total and cleaved caspase 1 (Additional file 5). A significant increase in cathepsin B release from HBE cells was also confirmed by immunohistochemistry (Additional file 6). Treatment of HBE cells with caspase-1 inhibitor (z-WEHD-FMK) and lysosomal protease cathepsin B inhibitor (CA- 074Me) either alone or in combination significantly protected the cells from MWCNT-induced toxicity (Figure 2C). Further, we demonstrated that siRNA against NLRP3 significantly reduced cell death (Figure 2D) of HBE cells confirming its role in the cytotoxic responses induced by MWCNTs.

\section{Mechanism of MWCNT-induced inflammatory response}

A significant increase in the release of inflammatory mediators (IL-1 $\beta$, IL-18 and IL-8) in cell culture supernatants was observed after 24 hours of MWCNT exposure (Figure $3 \mathrm{~A}-\mathrm{C}$ ). An increase in the levels of IL-1 $\beta$ and IL- 8 were observed even at non-cytotoxic dose (with 2 out of three tested methods) suggesting an inflammatory response in living cells, as opposed to cytokine release from ruptured cells. However, no significant change in the levels of GRO- $\alpha$, IP-10, IL-6, and IL-12 was observed, while IFN- $\gamma$, MIP-1 $\alpha$, RANTES and TNF- $\alpha$ were only detected in control LPS treated cells (data not shown). A time course (16, 24 and 48 hours) of inflammatory mediator production after MWCNT exposure is presented in Additional file 7. MWCNTinduced increase in IL-1 $\beta$ production was significantly reduced after pre-treatment with glycine (an inhibitor of pore formation), or caspase- 1 and cathepsin B inhibitors (Figure 3D). Further, we demonstrated that siRNA against NLRP3 significantly reduced IL-1 $\beta$ production (Figure 3E) by HBE cells confirming the role of NLRP3 inflammasome in the cytotoxic and inflammatory responses induced by MWCNT. We also measured levels of IL-18 and IL-8 in the supernatants of NLRP3 transfected cells and confirmed that IL-18 production was indeed inflammasome dependent (Figure 3F) while IL-8 production is not effected by NLRP3 knockout (Figure 3G). 

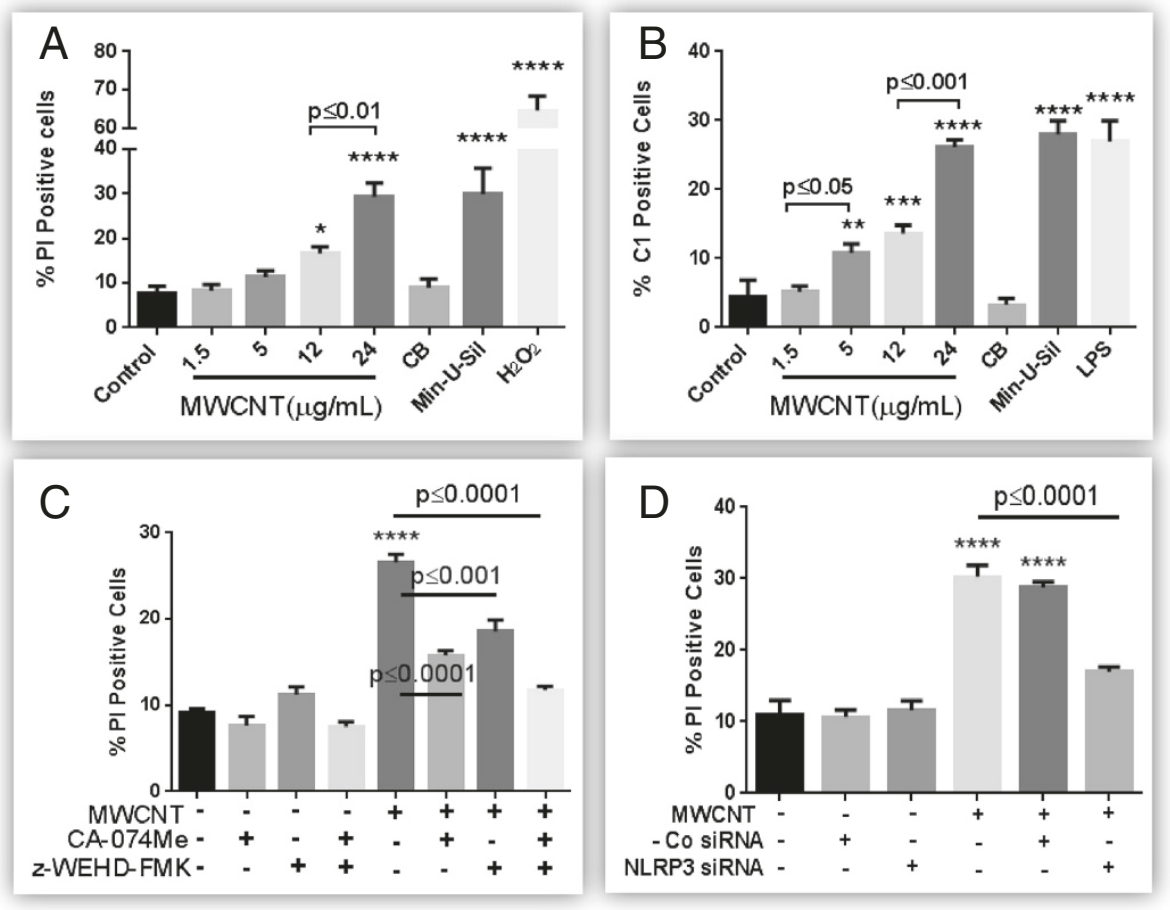

Figure 2 MWCNT induce pyroptosis in HBE cells. A) A dose response of MWCNT (1.5-24 $\mu \mathrm{g} / \mathrm{mL}$ equivalents $\left.0.37-6.0 \mu \mathrm{g} / \mathrm{cm}^{2}\right)$ induced cell death after 24 hours exposure. Cells were analyzed by flow cytometry after labeling with PI. CB (24 $\mu \mathrm{g} / \mathrm{mL})$ and Min-U-Sil $(100 \mu \mathrm{g} / \mathrm{mL})$ were used as negative and positive particle controls respectively. $\mathrm{H}_{2} \mathrm{O}_{2}(1 \mathrm{mM})$ was used as positive control for oxidative stress induced cells death. B) Caspase-1 activation in HBE cells after 24 hours MWCNT exposure, analyzed by flow cytometry. CB $(24 \mu \mathrm{g} / \mathrm{mL})$ was used as negative control while Min-U-Sil ( $24 \mu \mathrm{g} / \mathrm{mL})$ and LPS $(1 \mu \mathrm{g} / \mathrm{mL})$ were used as positive controls. C) Protection of cell death using specific inhibitors for cathepsin B (CA-074ME, $10 \mu \mathrm{M})$ and caspase-1 (Z-WEHD-FMK, $50 \mu \mathrm{M})$. Cells were pre-treated (for 1 hour) with these inhibitors before treatment with MWCNT $(24 \mu \mathrm{g} / \mathrm{mL})$ in the presence of inhibitor for further 24 hours and analyzed by flow cytometry. D) Modulation of cell death by specific siRNA against NLRP3 inflammasome. Transfection of HBE cells was performed using either specific siRNA against NLRP3 inflammasome or a nonspecific negative control siRNA. Cells were treated with MWCNT $(24 \mu \mathrm{g} / \mathrm{mL}$ ) for 24 hours. Cell death was measured by flow cytometry after labeling with PI. Data were analyzed by analysis of variance (ANOVA) followed by Tukey's post hoc test. Graphs show average \pm SEM of three independent experiments with triplicate of each conditions, ${ }^{*} \mathrm{p}<0.05,{ }^{* *} \mathrm{p}<0.01,{ }^{* * *} \mathrm{p}<0.001,{ }^{* * *} \mathrm{p}<0.0001$ (between media-treated control and treatments).

ROS production and its role in MWCNT-induced toxicity We observed significant dose and time-dependent production of ROS after exposure to MWCNT (Figure 4A). Time dependent phosphorylation of nuclear factor-kappa B (NF-kB) was also observed after MWCNT exposure (Figure 4B). NF- $\mathrm{kB}$ phosphorylation, loss of mitochondrial membrane potential $(\Delta \Psi \mathrm{m})$ and lipid peroxidation after MWCNT exposures were significantly reduced after utilizing antioxidants (N-acetylCysteine (NAC) and Catalase poly ethylene glycol (Cat Peg)) (Additional file 8A-C). Cytotoxic effects of MWCNT were successfully abolished using NAC or Cat peg (Figure $4 \mathrm{C}$ ). Moreover, IL-1 $\beta$ production was completely inhibited by QNZ (NF- $\mathrm{\kappa B}$ inhibitor) in addition to NAC and Cat peg (Figure 4D). It is noteworthy that ROS and inflammasome activation are well-established triggers for inflammasome assembly and cytokine production and all the known triggers of NLRP3 activation are ROS inducers [28].

\section{Conditioned medium from MWCNT-treated HBE cells induce fibroblast proliferation and Pro-fibrotic gene expression}

Pro-fibrotic response was confirmed by evaluating fibroblast proliferation by a recently validated in vitro assay and measuring gene expression for TIMP-1, TN-C, PC1 and OPN. A conditioned media (CM) approach was developed to analyze the role of epithelial derived factors in fibroblast gene expression as co-culturing of epithelial cells and fibroblasts was not technically possible (Figure 5A). An increase in fibroblast proliferation was observed after exposure to CM from MWCNT treated HBE cells (Figure 5B). We observed a significant increase in fibroblast gene expression of TIMP-1, TN-C, PC1 and OPN after CM exposure for $48 \mathrm{~h}$ (Figure $5 \mathrm{C}$ ). TGF- $\beta$, a known inducer of fibrotic response was used as a positive control. It is noteworthy that we did not observe an increase in gene expression of TGF- $\beta$ itself after exposure to conditioned medium 


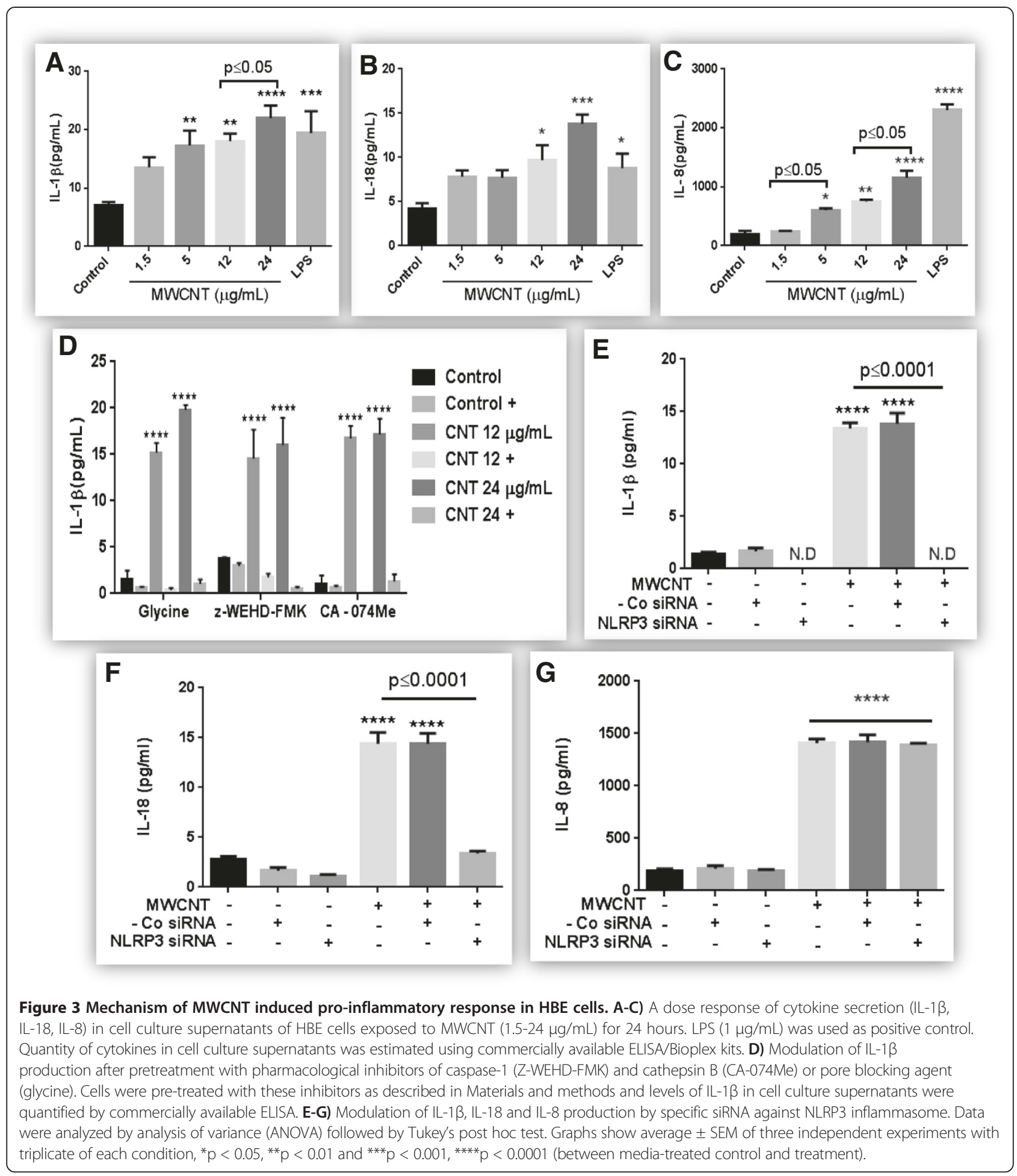

from epithelial cells treated with MWCNT (Figure 5C). The pro-fibrotic gene expression in fibroblasts depended on NLRP3 inflammasome activation in HBE Cells, since a significant decrease in the expression of TIMP-1, TN-C, PC1 and OPN was observed when CM from $\mathrm{HBE}$ cells transfected with NLRP-3 siRNA was used (Figure 6A-D). Again CM from NLRP3 siRNA transfected cells did not lead to any change in gene expression of TGF- $\beta$ (Figure $6 \mathrm{E}$ ). The role of IL-1 $\beta$, IL-18 and IL-8 was established in the observed responses utilizing neutralizing antibodies against them (Figure 7A-C). IL-1 $\beta$ played a significant role in the induction of tested pro- 

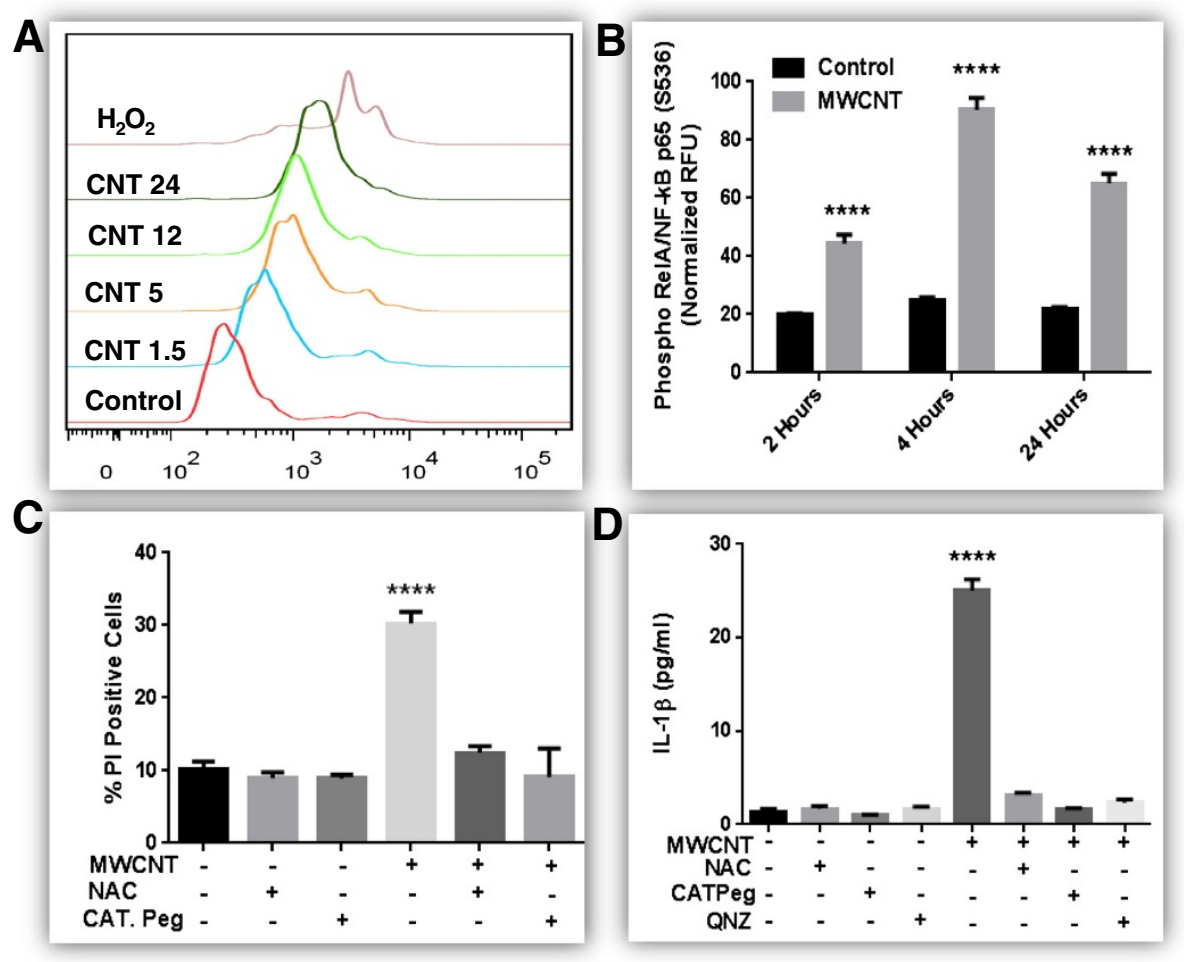

Figure 4 Role of ROS production in MWCNT induced toxicity. A) Dose response of ROS production. HBE cells were treated with different doses of MWCNT (1.5-24 $\mu \mathrm{g} / \mathrm{mL}$ equivalents $\left.0.37-6.0 \mu \mathrm{g} / \mathrm{cm}^{2}\right)$ for 24 hours. Hydrogen peroxide (1 mM) was used as positive control. ROS were labeled with HE and analyzed by flow cytometry. At least 10,000 cells/events excluding debris were captured. B) Time course analysis of NF-KB (REL A/P65) phosphorylation in HBE cells after exposure to $24 \mu \mathrm{g} / \mathrm{mL}$ MWCNT for different time points. Cells based ELISA was performed according to manufacturers recommendations. C) Modulation of MWCNT induced cell death with antioxidants (NAC and CAT Peg). Cells were pre-treated with $5 \mathrm{mM}$ NAC or CAT Peg (1000 I.U) (30 minutes) and then exposed to MWCNT ( $24 \mu \mathrm{g} / \mathrm{mL}$ ) for 24 hours in the presence of antioxidants. Cell death analysis was performed using flow cytometry. D) Modulation of MWCNT induced IL-1 $\beta$ production with antioxidants (NAC and CAT Peg) and NF-KB inhibitor (QNZ). Cells were pre-treated with 5 mM NAC, CAT Peg (1000 I.U) (30 minutes) or QNZ (10 nM) and then exposed to MWCNT (24 $\mu \mathrm{g} / \mathrm{mL})$ for 24 hours in the presence of inhibitors. Cytokine production was analyzed by commercially available ELISA. Data were analyzed by analysis of variance (ANOVA) followed by Tukey's post hoc test. Graphs show average \pm SEM of three independent experiments with triplicate of each condition, ${ }^{*} p<0.05$, ${ }^{* *} p<0.01,{ }^{* * *} p<0.001,{ }^{* * *} p<0.0001$ (between media-treated control and treatment).

fibrotic markers (TN-C, TIMP-1 and OPN). Interestingly, all cytokines appear to contribute in the induction of TN-C as their neutralization afforded only partial protection.

\section{Discussion}

In the present study we mechanistically investigated MWCNT-induced cell injury and elaborated its role in the induction of a profibrotic response. We found that MWCNT induce pyroptosis and inflammasome activation in primary human bronchial epithelial cells. Furthermore, we describe a mechanism through which profibrotic gene expression is induced in fibroblasts in response to inflammasome-derived factors from injured bronchial epithelial cells. An overview of all these mechanisms is presented in Figure 8 . To the best of our knowledge this is first report confirming inflammasome dependent pro-fibrotic response after MWCNT exposures to the primary $\mathrm{HBE}$ cells.
Some literature reports have discussed inflammasome activation in LPS stimulated myeloid cells (mostly cell lines) after nanotube exposures [29,30]. Myeloid cells are known to produce enormous amounts of cytokines after endotoxin stimulation, however it has always been difficult to establish the relevance of the large amounts of endotoxin used in vitro with realistic in vivo exposures. Our study differs from above mentioned work in four important aspects: 1) We used primary human bronchial epithelial cells; 2) We uncovered the molecular mechanism of pyroptosis in HBE cells; 3) We observed inflammasome activation without prior priming with LPS; and 4) We uncovered the biological significance of the inflammasome activation after MWCNT exposure as a trigger for a pro-fibrotic response. Moreover, it is important to note that we observed the pro-fibrotic response without significant induction of TGF- $\beta$ which has been shown to be induced after MWCNT exposure 

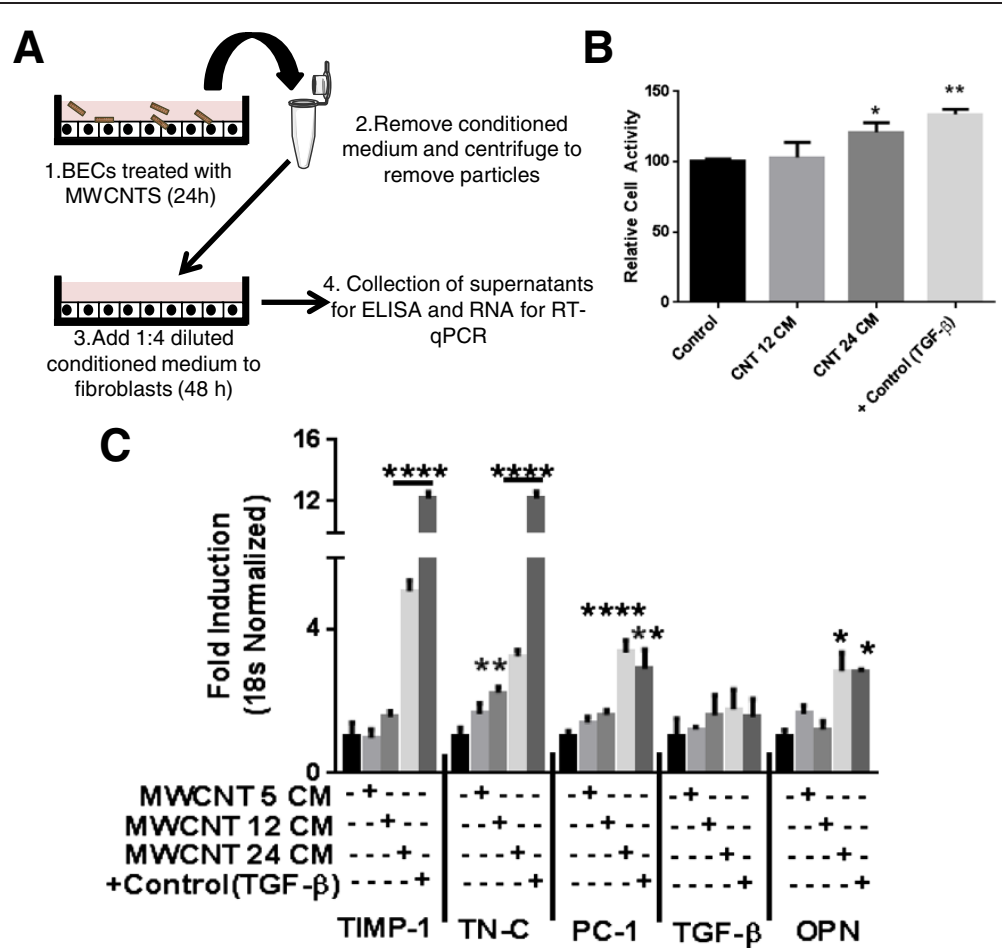

Figure 5 HBE cells conditioned medium induces fibroblast proliferation and profibrotic gene expression. A) Experimental protocol for conditioned media experimentation. HBE cells were treated with different doses of MWCNT (12, $24 \mu \mathrm{g} / \mathrm{mL}$ equivalents $\left.3.6 \mu \mathrm{g} / \mathrm{cm}^{2}\right)$ for 24 hours, cell culture supernatants were removed, centrifuged and diluted 1:4 with DMEM/F-12 medium (without serum). Fibroblasts were grown till near confluence and serum starved for 24 hours then exposed to conditioned medium from epithelial cells for 48 hours. mRNA was extracted from these cells to perform pro-fibrotic gene expression analysis using real time quantitative RT-PCR. B) Fibroblast proliferation assay after CM exposure for 48 hours. TGF- $\beta$ (10 ng/mL) was used as a positive control. C) Dose response analysis of TIMP-1, TN-C, PC-1, TGF- $\beta$ and OPN expression in MRC-5 cells after CM exposures. Data were analyzed by analysis of variance (ANOVA) followed by Tukey's post hoc test. Graphs show average \pm SEM of three independent experiments with triplicate of each condition, ${ }^{*} p<0.05,{ }^{* *} p<0.01$, ${ }^{* * *} p<0.001$, ${ }^{* * * *} p<0.0001$ (between media-treated control and treatment).

in rodent studies as well as studies with cell lines $[8,13]$. This indicates a potential limitation of these models to predict human exposures/responses after MWCNT exposure.

Growing evidence confirms a significant contribution of airway epithelium in pulmonary immune responses to inhaled pollutants/allergens [31,32]. It has been shown that epithelium-derived factors significantly contribute in the pathogenesis of a variety of respiratory disorders like asthma, idiopathic pulmonary fibrosis and chronic obstructive pulmonary disease $[33,34]$. This study further confirms the significance of primary human epithelial cells as contributors to the innate immune response, as we observed a significant production of inflammatory mediators from these cells even after non-cytotoxic MWCNT exposures. An exuberant activation of epithelial cells can lead to an uncontrolled response and thus could have deleterious consequences. We further attempted to activate epithelial cells with LPS to see if cytotoxic responses increase further. Our data indicate these cells are stimulated to their maximum and cannot be further stimulated (Additional file 9A). This confirms that production of low amount of cytokines is indeed a strategy by the body to avoid uncontrolled immune response. However, it is worth mentioning that even the low amounts of inflammatory mediators produced by epithelial cells have significant biological impact and can lead to fibroblast proliferation and pro-fibrotic gene expression. We observed no significant effect of LPS priming on the release of IL- $1 \beta$ and IL-18 from BECs (Additional file 9B-C). These findings are in line with recently reported observations from silica exposed bronchial cells [35]. Interestingly, we observed significant increase in the production of IL-8 after LPS priming (Additional file 9C). This on one hand confirms differential signaling cascades for IL-8 production, and on the other hand further affirms that no increase in IL- $\beta$ was a true biological response and could not be attributed to LPS.

Pro-fibrotic response is characterized by increased fibroblast proliferation and excessive ECM deposition either due to excessive production or impaired turnover. We studied expression of important components of airway remodeling i.e. TN-C, OPN, PC-1 and TIMP-1. We demonstrate here a significant increase in expression of these 

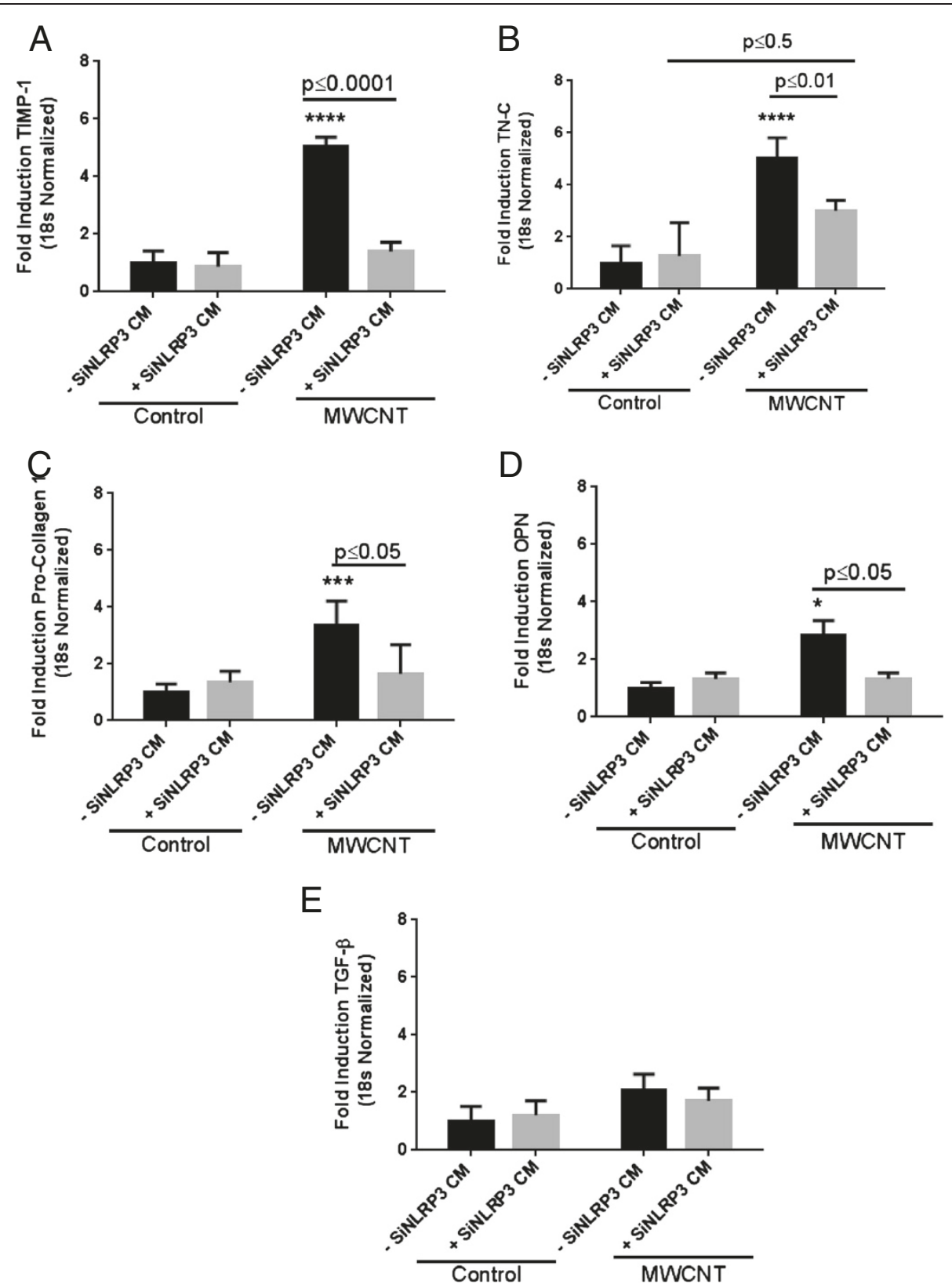

Figure 6 Role of NLRP3 inflammasome activation in HBE cells in inducing a pro-fibrotic gene expression in fibroblasts. A-E) Modulation of TIMP-1, TN-C, PC-1, OPN and TGF- $\beta$ using conditioned media from HBE cells transfected with siRNA against NLRP-3 inflammasome. Data were analyzed by analysis of variance (ANOVA) followed by Tukey's post hoc test. Graphs show average \pm SEM of three independent experiments with triplicate of each conditions, ${ }^{*} p<0.05,{ }^{* *} p<0.01,{ }^{* * *} p<0.001,{ }^{* * *} p<0.0001$ (between media-treated control and treatment).

markers after exposure to conditioned medium from MWCNT treated HBE cells. Increased levels of OPN, PC-1 and TIMP-1 are noted in rodent lungs in bleomycin induced pulmonary fibrosis [36-38]. TN-C is prototypic family member of Tenascin family of extracellular matrix glycoproteins. TN-C is highly expressed under pathological conditions such as inflammation, infection, tumorigenesis and wound healing [39]. Recently, it has been shown that TN-C deficiency attenuates TGF- $\beta$-mediated fibrosis following rodent lung injury [40]. In patients with asthmatic inflammation enhanced $\mathrm{TN}-\mathrm{C}$ expression correlates with grade of bronchial inflammation of mast cells and eosinophils [41]. TIMPs inhibit the activity of matrix metalloproteinases and thus play and important role in maintaining a balance between ECM deposition and degradation. TIMP-1 is an important member of the TIMP family and has known association with different disease processes in human airways. Increased TIMP-1 levels 

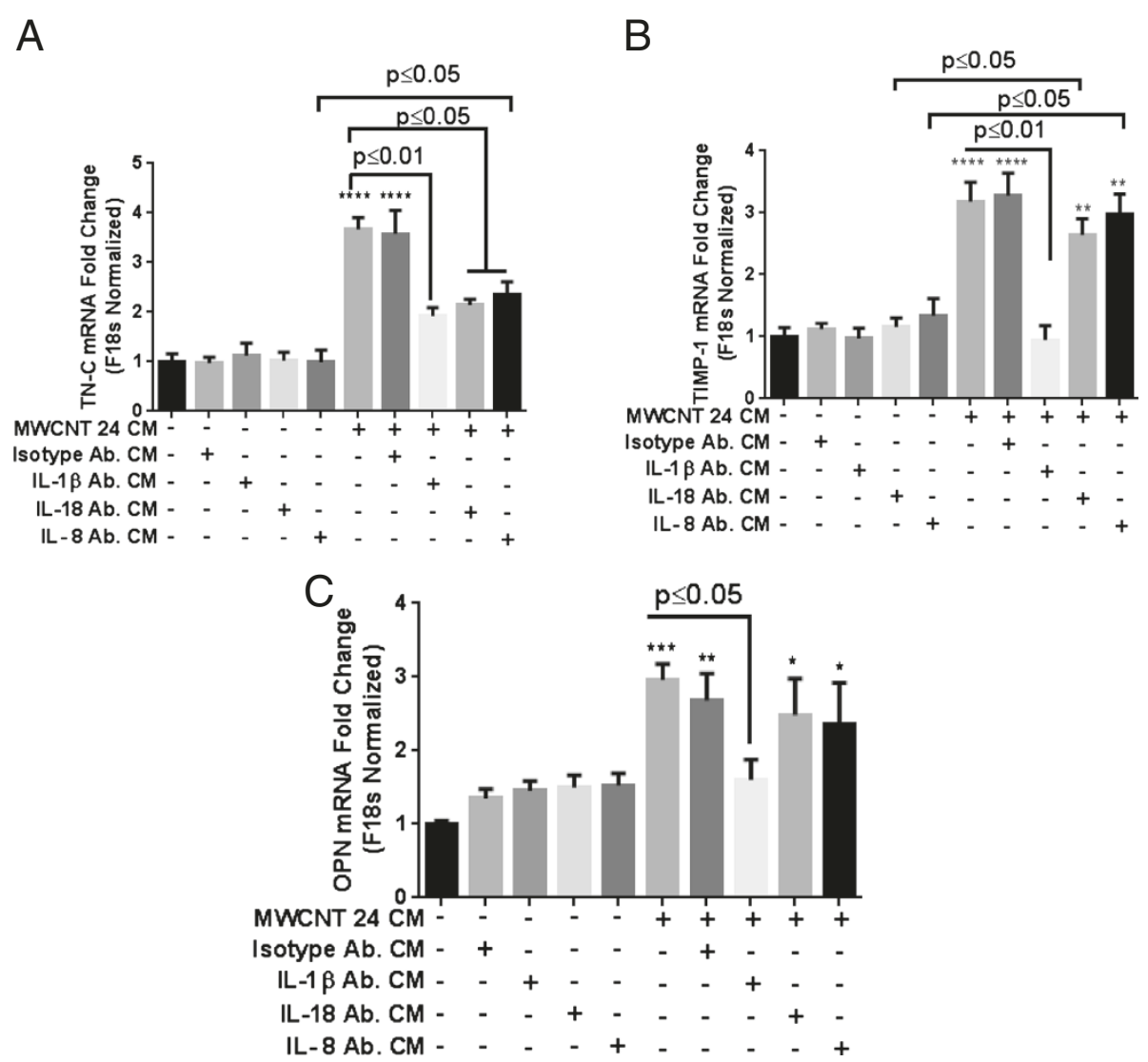

Figure 7 Role of inflammatory cytokines in conditioned medium from MWCNT treated HBE cells in inducing pro-fibrotic gene expression. Conditioned medium from MWCNT-treated epithelial cells (24 hour exposure at $24 \mu \mathrm{g} / \mathrm{mL}$ ) was incubated with neutralization antibody against $\mathrm{IL}-1 \beta(5 \mu \mathrm{g} / \mathrm{mL})$, IL-18 $(5 \mu \mathrm{g} / \mathrm{mL})$, or IL-8 $(10 \mu \mathrm{g} / \mathrm{mL})$ at $37^{\circ} \mathrm{C}$ for 30 minutes before adding to the MRC-5 cells. Gene expression of $\left.\mathbf{A}\right) \mathrm{TN}-\mathrm{C}$ B) TIMP-1 and C) OPN after 48 hours of exposure was evaluated by real time quantities RT-PCR. Data were analyzed by analysis of variance (ANOVA) followed by Tukey's post hoc test. Graphs show average \pm SEM of three independent experiments with triplicate of each conditions, ${ }^{*} p<0.05,{ }^{* *} p<0.01,{ }^{* *} p<0.001,{ }^{* * *} p<0.0001$ (between media-treated control and treatment).

associated with airflow obstruction were found in sputum from subjects with asthma and chronic bronchitis [42]. It was noted that decreased MMP-9/TIMP-1 ratio lead to an increase in airway wall thickness causing pro-fibrotic response through increased matrix deposition [43]. It is worth mentioning that transcriptomic analysis revealed TIMP-1 induction in mouse lungs after MWCNT instillation, however monocultures of mouse lung epithelial cells did not show an increase in TIMP-1 mRNA [44]. This further confirms the need to study cellular interactions to accurately describe the effects of nanomaterials. Our results of increased mRNA expression of OPN are in line with reports describing its over expression after particle and fibre exposures and in granulomatous lung diseases [45,46]. OPN is a matricellular protein mediator which is upregulated in patients of idiopathic pulmonary fibrosis [47]. Increased levels of OPN cause fibroblast proliferation, migration and adhesion [48]. Taken together, these literature findings when combined with our expression data indicate a plausible mechanism of airway remodeling after exposure to conditioned medium from MWCNT treated HBE cells.

We also characterized the role of NLRP3 inflammasome activation in HBE cells as a modulator of the pro-fibrotic response in fibroblasts. NLRP3 inflammasome activation has been shown in various mammalian cell types (macrophages, dendritic cells, monocytes, epithelial cells, fibroblasts, keratinocytes and neurons) in response to diverse stimuli, including microbes, viral RNA, ATP, uric acid crystals, environmental particles and fibres [29,49-53]. Among various members of the inflammasome family, NLRP3 has shown to be particularly responsive to dangerassociated molecular patterns (DAMPS) and fibres and particles including nanomaterials in addition to detecting pathogen associated molecular patterns (PAMPS) [50,54]. Previously, it was reported that MWCNT-induced macrophage activation promotes pulmonary fibrosis through the TGF- $\beta /$ Smad pathway [8]. Using primary human cells we 


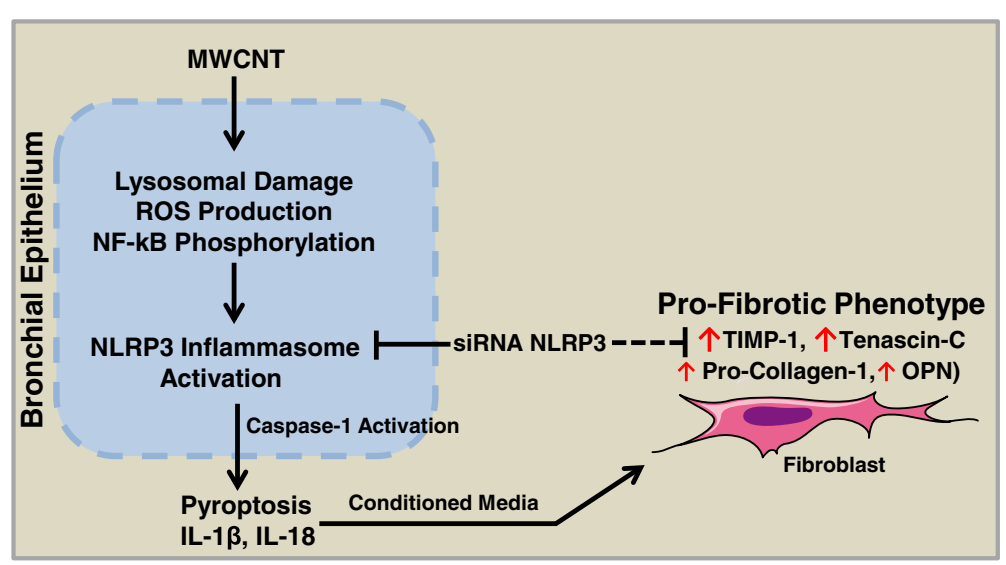

Figure 8 MWCNT-induced cell death (pyroptosis) mechanisms in primary HBE cells and its contribution in pro-fibrotic gene expression in fibroblasts. Internalization of MWCNT in HBE cells leads to lysosomal damage, release of cathepsin B, ROS production, NF-KB phosphorylation, NLRP3 inflammasome activation and their inhibition can successfully abolish MWCNT-induced toxicity. NLRP3 inflammasome derived factors from HBE cells induce pro-fibrotic (TN-C, TIMP-1, PC-1 and OPN) gene expression in MRC-5 cells.

describe here a novel mechanism through which epithelial cells can initiate a profibrotic response through activation of the NLRP3 inflammasome. Recently, cristobalite silica induced inflammasome activation in epithelial cells was shown to induce fibroblast proliferation [35]. Moreover, it was demonstrated that NLRP3 and ASC deficient mice did not develop pulmonary fibrosis after bleomycin exposure whereas wild type mice had increased collagen deposition the lungs [55]. Taken together the results demonstrate that the NLRP3 inflammasome can orchestrate fibrosis in both sterile and pathogen-driven conditions [56]. The NLRP3 inflammasome has been implicated in the pathogenesis of various disorders like asbestosis, silicosis, gout, Alzheimer's disease and diabetes, mostly through the production of IL- $1 \beta \quad[49,50,53,57]$. We demonstrate here that IL-1 $\beta$ present in conditioned medium from epithelial cells plays a significant role in inducing pro-fibrotic gene expression. Indeed, IL-1 $\beta$ is known to induce TIMP-1 expression through regulation of AP-1and/or NF- $\mathrm{KB}$ in fibroblasts [58]. Moreover, increased expression of OPN is described after exposure to inflammatory cytokine such as IL-1 $\beta$ [59]. Interestingly, we show that IL- $1 \beta$ as well as IL-18 and IL- 8 contribute in the induction of TN-C. It is worth mentioning that conditioned medium from HBE cells did not induce toxicity or ROS production in fibroblasts, thus ruling out oxidative stress as an effector mechanism for fibroblast proliferation or pro-fibrotic gene expression (Additional file 10). Taken together these results clearly demonstrate that inflammasome downstream (IL-1 $\beta$ and IL-18) as well as inflammasome independent IL-8 contributes in the pro-fibrotic response after MWCNT exposure. This gene expression appear to be mainly derived through IL-1 $\beta$ (neutralization reduces expression of TIMP-1, OPN and TN-C) whereas other cytokines (IL-18 and IL-8) appear to have only minor role (neutralization only protects partially from $\mathrm{TN}-\mathrm{C}$ overexpression).

The NLRP-3 inflammasome is well known platform for the activation of caspase- 1 which is driven by induced proximity. Indeed, in addition to its role in activation of IL-1 $\beta$ and IL-18, overt inflammasome activation can also lead to cell death through caspase-1 (Pyroptosis) [60]. Our results are in line with recent reports describing caspase-1 activation in HBE cells or myeloid cells (monocytes and macrophages) after exposure to carbon black nanoparticles, silver nanoparticles, cristobalite silica particles, carbon nanotubes and cholesterol crystals [29,30,35,61,62]. Our finding of caspase-1 activation after nanotube exposure without priming with LPS is in line with recent literature describing caspase- 1 activation after silica exposure in epithelial cells [35]. However, using primary HBE cells, we have additionally explored the expression of profibrotic genes and verified the role of different cytokines using specific neutralizing antibodies in MWCNT induced pro-fibrotic response. Moreover, we demonstrate that the pro-fibrotic gene expression occur without de novo TGFbeta expression. We did not find any increase in caspase $3 / 7$ or RIP 1 levels, thus confirming the cell death modality as pyroptosis and not apoptosis or necroptosis (Additional file 11). Moreover, we demonstrate here that inflammasome activation and resulting IL- $1 \beta$ secretion occur without priming by TLR ligation. These results are in agreement with recent findings that silica particles and particulate matter exposure can lead to inflammasome activation without LPs priming [35,54]. NLRP3 inflammasome activation is sometimes described as multistep process, requiring TLR priming to increase expression of pro IL-1beta and IL-18 (through NF-kB phosphorylation) before actual inflammasome assembly. However, various other triggers e.g. oxidative stress can also activate NF-kB 
leading to increase production of these cytokines. It is an ongoing debate whether NLRP3 inflammasome activation absolutely require TLR-agonist priming. For instance, it has been shown that NLRP3 assembly and resulting IL-1 $\beta$ secretion can occur after exposure to various stimuli without engaging TLR receptors [63-65]. These studies propose various alternate pathways to explain inflammasome assembly without TLR priming includes activation through danger associated molecular patterns (DAMPS), P2X7 receptor, serum amyloid A.

\section{Conclusions and perspectives}

In conclusion, the results of present study elucidate the significance of NLRP3 inflammasome activation in epithelial cells as a key mediator of pro-fibrotic gene expression in MRC-5 cells. Moreover, these results indicate that MWCNT-induced bronchial epithelial injury shares common mechanisms with various well-known respiratory pathologies, such as asthma, COPD, and idiopathic pulmonary fibrosis. This further raises the possibility of modulation of pre-existing disorders by nanotubes exposure in susceptible human populations (already shown to occur in rodent models). Lastly, this study further confirms the significance of primary human epithelial cells as contributors towards the innate immune response. Further studies to elucidate the role of differentiation in cell injury mechanisms, using ex-vivo differentiated bronchial epithelial cells at air-liquid interfaces, are currently in progress in our laboratory. More in depth studies using translational approaches are needed for further clarifying the human health impacts of nanotubes exposures.

\section{Materials and methods}

\section{Nanomaterials and characterization}

Commercially available MWCNT (0.5-40 $\mu \mathrm{m}$ length and 10-30 nm external diameter), prepared by chemical vapor deposition (CVD) method, were utilized in this study (Helix Material Solutions, Inc., Richardson, TX). More details about physical characteristics of the bulk materials used in this study can be found in supporting information. Carbon black (CB) NPs of $90 \mathrm{~nm}$ diameter (99.9\% pure, spherical shape) were used as chemical composition negative control and were purchased from Evonik (formerly Degussa). Crystalline Silica particles (Min-U-Sil (99.2\% pure $\alpha$-Quartz) were used as particulate positive control (US Silica Company, Berkeley, CA). These materials have been used extensively for in vitro and in vivo exposures to study the toxicity nanomaterials and their characteristics have already been described $[18,66,67]$.

\section{Nanomaterial suspensions}

Stock suspensions of nanomaterials were made at $2 \mathrm{mg} / \mathrm{mL}$ concentration in BEGM media containing $0.01 \mathrm{mg} / \mathrm{mL}$
Dipalmitoylphosphatidylcholine (DPPC) and $0.6 \mathrm{mg} / \mathrm{mL}$ Bovine serum Albumin (BSA), both from Sigma Aldrich. Studies were conducted to know the impact of these dispersants on the viability, mitochondrial activity and inflammation in HBE cells. These results are presented in Additional file 12. Our results confirmed no harmful effect of these additives on the studied parameters at all the tested doses. This dispersion protocol is already described to yield maximum suspension stability and mimic more closely the in vivo lung surfactant fluid [13]. All exposure suspensions were freshly prepared from this stock solution after sonication for 12 minutes at $235 \mathrm{~W}$ (20 s pulses with a 5 s pause) using a Mesonix S 4000 cuphorn sonicator (Qsonica LLC, Newtown, CT, USA). After sonication nanomaterials were suspended in cell culture medium and used to expose cells within 5 min after vortexing. Dynamic light scattering analysis was performed to evaluate size distribution and zeta potentials of nanomaterial suspensions in cell culture medium using ZetaSizer Nano (Malvern Instruments, Westborough, MA, USA) as described by us previously [68]. Electrophoretic mobility was converted into zeta potential using the HelmholtzSmoluchowski equation.

\section{Cells and culture conditions}

$H B E$ cells were purchased from Lonza (Walkersville, MD USA) under the trade name of Normal Human Bronchial Epithelial Cells. Cells from 5 individuals were utilized in the present study and all experiments were performed between passage $3-4$. These cells were cultivated in BEGM media (BEBM media supplemented with $5 \mu \mathrm{g} / \mathrm{mL}$ insulin, $0.5 \mathrm{ng} / \mathrm{mL}$ hEGF, $0.5 \mu \mathrm{g} / \mathrm{mL}$ hydrocortisone, $0.5 \mu \mathrm{g} / \mathrm{mL}$ epinephrine, $50 \mu \mathrm{g} / \mathrm{mL}$ gentamycin, $50 \mu \mathrm{g} / \mathrm{mL}$ amphoteracin $\mathrm{B}, 10 \mu \mathrm{g} / \mathrm{mL}$ transferrin, $6.5 \mathrm{ng} / \mathrm{mL}$ triidotyronin, $0.13 \mathrm{mg} / \mathrm{mL}$ bovine pituitary extract (all supplied by Lonza) and $100 \mu \mathrm{g} / \mathrm{mL}$ penicillin and streptomycin (Sigma Aldrich). Cells were cultivated on non coated plastic material (recommended by the supplier) at a density of 20,000 cells per $\mathrm{cm}^{2}$ and kept in an incubator at $37^{\circ} \mathrm{C}, 5 \%$ $\mathrm{CO}_{2}$, and $95 \%$ relative humidity. Cells were exposed to nanomaterials after 72 hours of culture (nearly 90\% confluence). In the experiments involving pharmacological inhibitors, cells were pre-treated with fresh media containing inhibitors for desired period of time and then treated with NP suspensions in the presence of inhibitors. Following inhibitors were used in different experiments: z-WEHD-FMK (Caspase-1 inhibitor) ( $\mathrm{R}$ and D Systems, Minneapolis MN), CA-074Me (Cathepsin B inhibitor) (Sigma-Aldrich, St. Louis, MO), Staurosporine (apoptosis positive control) (Sigma-Aldrich, St. Louis, MO).

For cytokine neutralization assays, cells were incubated for 30 minutes with neutralizing antibodies (anti IL-1 $\beta$, anti IL-8 (both from $\mathrm{R}$ and D Systems, Minneapolis $\mathrm{MN}$ ) or anti IL-18 (MBL, Japan) before treatment with 
MWCNT (in the presence of antibodies) for further 24 hours.

MRC-5 fibroblasts were purchased from American Type Culture Collection (ATCC) and maintained in DMEM/ F12 medium supplemented with 10\% Fetal Calf Serum and $100 \mu \mathrm{g} / \mathrm{mL}$ penicillin and streptomycin. Recently, it was demonstrated that these cells respond to nanoparticle exposures in a similar way as primary human lung fibroblasts [69]. Cells were cultured in 12 well plates till confluence and then serum starved for 24 hours. Cells were exposed to a mixture of 1 part CM (from nanotubes treated HBE cells) and 4 parts DMEM/F12 medium for 48 hours. At the end of exposure period cells were lysed to collect mRNA for real time RT-PCR analyses. TGF- $\beta$ $(10 \mathrm{ng} / \mathrm{mL}$ ) was used as positive control in for fibrosis experiments. We first attempted co-culturing primary $\mathrm{HBE}$ cells and MRC-5 fibroblast cells. However, this approach was not successful as either medium required for optimal growth of one type of cells causes either death or changed morphology of the other cell type. Our experimentation indicated that primary $\mathrm{HBE}$ cells are very sensitive to serum and media other than BEGM. We observed that serum containing DMEM (even as low as 10\%) results in changes in morphology and causes cell death (data not shown). On the other hand fibroblasts react to the addition of BEGM with morphological changes, altered metabolic activity and cell death (data not shown). We therefore adapted a conditioned medium approach to overcome this hurdle. It is noteworthy that this is also a more physiologically relevant approach as epithelial cells are directly exposed to nanomaterials while fibroblasts are mostly exposed to epithelial secretions and only come in contact with nanomaterials in case of damaged/denuded epithelia. This approach has already been reported elsewhere to study the toxicity of silica particles [35]. We verified that CM did not introduce toxicity and ROS production in fibroblasts (Additional file 10).

\section{Transmission electron microscopy}

HBE cells were grown in two chamber cell culture slides till sub-confluence and treated with different concentrations of MWCNT for $24 \mathrm{~h}$. At the end of treatment period, cells were fixed in $3 \%$ glutaraldehyde and processed for TEM analysis as described previously [68]. Thin sections $(80 \mathrm{~nm})$ were cut, placed on formvar copper grids and stained with uranyl acetate and lead citrate. After staining, the sections were examined on a FEI Tecnai $110 \mathrm{kV}$ microscope at $80 \mathrm{kV}$, and digital photomicrographs were taken.

\section{Validation of In vitro assays}

Moreover, necessary measures (using alternate methods and controls) were taken to avoid artifacts introduced by the nanomaterials in spectrophotometric and florescent assays. Cytokine ELISA assays were standardized by using an approach described previously [70]. Known amounts of cytokine standards were incubated with different nanotubes concentrations to verify possible adsorption of cytokines on nanotubes. Particle only controls were also run in parallel to verify the impact of particles on absorbance measurements. Cytotoxicity results were verified using three independent techniques i.e. LDH assay, trypan blue exclusion cell counts and flow cytometry using propidium iodide. We observed significant impact of nanotube concentrations higher than $24 \mu \mathrm{g} / \mathrm{mL}$ on absorbance (data not shown). We used approaches described recently in detail to avoid interferences with flow cytometry assays (PI and ROS production) [71]. Particles were incubated with fluorochromes to rule out their binding onto particle surfaces. No uptake of PI/HE was observed for any type of particles used in this study. We observed that flow cytometry was least impacted by the nanotubes and it gave most statistically reliable readings in terms of highest number of cell counts per conditions.

\section{Flow cytometry}

Cell death was quantified in MWCNT treated cells by flow cytometery using propidium Iodide (PI) probe which detects the integrity of cell membrane. Briefly, supernatants were collected at the end of treatment period and cells were trypsinated using $0.025 \%$ trypsin-EDTA (Invitrogen). The action of trypsin was inhibited using $10 \%$ fetal bovine serum (Sigma Aldrich, St. Louis, MO, USA) and cells were mixed with respective supernatant samples. Cells were centrifuged for 5 minutes at $400 \mathrm{~g}$ and resuspended in cell culture media containing PI ( $2.5 \mu \mathrm{g} / \mathrm{mL}$ final concentration). Analysis was performed using BD FACSAria II equipment at $488 \mathrm{~nm}$ excitation and $615 \mathrm{~nm}$ emission wavelengths. After eliminating cell debris at least 10000 cells were analyzed to determine the percentage of PI positive cells.

\section{Caspase- 1 assay}

Caspase-1 activation in HBE cells was quantified using FAM-FLICA $^{\mathrm{Tm}}$ Caspase-1 Assay (FAM-YVAD-FMK) kit (Immunochemistry Technologies, Bloomington, $\mathrm{MN}$ ). Cells were labelled according to manufacturers recommendation and analysis was performed using BD FACSAria II equipment. After eliminating cell debris at least 10000 cells were analyzed to determine the percentage of capase- 1 positive cells.

\section{Cytokine analysis}

The concentrations of IL-1 $\beta$, IL-18, IL-8, MCP-1 and IL-13 released into the culture supernatant after 16,24 or 48 hours MWCNT exposure were evaluated with either commercially available human enzyme-linked immunosorbent assay (ELISA) kit (R\&D Systems, Minneapolis 
$\mathrm{MN}$ ) or BD Bioplex assay system (BD Biosciences) according to manufacturers recommendations.

\section{siRNA for NLRP3}

Cells were transfected using Lipofectamine 2000 reagent (Block-iT Transfection Kit, Invitrogen) according to manufacturer's recommendation and incubated with specific $100 \mathrm{nM}$ siRNAs for 24 hours prior to nanomaterial exposures. Silencer select ${ }^{\circ}$ siRNA against NLRP3 (sense $5^{\prime}->3^{\prime}$ GCUUUGUCCUCGGUACUCAtt and UGAGUACCGAG GACAAAGCtg, Silencer select ${ }^{\circ}$ negative control \#2 siRNA (product number 4390846 Ambion $^{\circ}$ ) and BLOCK-iT ${ }^{\mathrm{mm}}$ Green Fluorescent Oligo for Lipid Transfection (transfection control, Invitrogen) were used. Inflammasome down regulation was verified with RT- $\mathrm{qPCR}$ and NLRP3 protein analyses (Additional file 13).

\section{ROS production}

ROS production was estimated by flow cytometery after staining with Hydroethidine (HE) probe as described by us previously [72]. After eliminating cell debris at least 10000 cells were analyzed to determine the percentage of HE positive cells. The graphic presentation of results was created using FlowJo Software (TreeStar Inc, Ashland, OR).

\section{Phospho REL A/p65 NF-kB ELISA}

Cell based human Phospho-Rel A/p65 (S536) immunoassay was performed according to manufacturers recommendations ( $\mathrm{R}$ and $\mathrm{D}$ Systems Minneapolis MN). Assay results were validated using immunohistochemistry for phospho p65 (data not shown) and by analyzing necessary controls as mentioned in cytokine estimation assay.

\section{Fibroblast proliferation assay}

Fibroblast proliferation was assessed 24 hours after exposure to MWCNT by a recently validated in vitro assay described in detail elsewhere [73]. We used $10 \mathrm{ng} / \mathrm{mL}$ TGF- $\beta$ as a positive control.

\section{Real time RT-PCR}

Total RNA was collected from adherent cell cultures using RNEasy Midi Kit (Qiagen, Germantown, MD) according to manufacturer's recommendations. Amount of RNA was quantified using NanoDrop (Thermo Fisher Scientific, USA). Reverse transcription (RT) reaction to obtain cDNA was performed with SuperScript III kit and oligo dTs (Invitrogen) exactly following manufacturer's recommendations. Final PCR reaction volume was $25 \mu \mathrm{L}$ containing Power SYBR Green Master Mix (Applied Biosciences), $1 \mu \mathrm{g}$ of cDNA and $500 \mathrm{nM}$ of each specific forward and reverse primer (Table 1). Data was collected on a Stratagene Mx3005P real-time PCR instrument (Agilent, CA, USA). Changes in expression
Table 1 Primer sequences used in the present study for qPCR analyses

\begin{tabular}{lll}
\hline Gene & Primers & Sequences $\left(\mathbf{5}^{\prime} \rightarrow \mathbf{3}^{\prime}\right)$ \\
\hline $18 \mathrm{~s}$ & Forward & GTAACCCGTTGACCCCATT \\
& Reverse & CCATCCAATCGGTAGTAGCG \\
OPN & Forward & CTGAAACCCACAGCCACA \\
& Reverse & TGTGGAATTCACGGCTGA \\
TN-C & Forward & AGGGCAAGTGCGTAAATGGAG \\
& Reverse & TGGGCAGATTTCACGGCTG \\
TIMP-1 & Forward & AGACCTACACTGTGGCTGTGAG \\
& Reverse & GACTGGAAGCCCTITCAGAG \\
PC-1 & Forward & CCAGAAGAACTGGTACATCAGCAA \\
& Reverse & CGCCATACTCGAACTGGAATC \\
TGF- $\beta$ & Forward & ACGCACCCTGTCTGACTACA \\
& Reverse & ACCTCTAAGACGGAGCACCA \\
NLRP3 & Forward & GGAGAGACCTITATGAGAAAGCAA \\
& Reverse & GCTGTCTTCCTGGCATATCACA \\
\hline
\end{tabular}

of target genes were determined by ddCt analysis, comparing expression to Ribosomal Protein (18 s) and normalizing to media control. Each fold expression represents an average of at least 3-5 biological replicates per treatment group. Following primers were used for different genes.

\section{Immunocytochemistry (ICH)}

ICH analysis was performed to evaluate Cathepsin B release and phosphorylation and nuclear translocation of RELA/P65 subunit of NF- $k$ B. Detailed method for the labelling has been published [72]. Following primary antibodies were employed: phosphor-NF-kB p65 (Ser536) (93H1) rabbit monoclonal antibody (Cell Signalling) (1:100), anti-cathepsin B (CB59-4B11,Sigma-Aldrich) (1:100). In case of non-conjugated primary antibodies, Alexa Fluor $488^{\circ}$ (1:500) was used as secondary antibody and nuclei were counterstained with Hoechst 33342 stain $(1 \mu \mathrm{g} / \mathrm{mL})$. Images were captured using a Zeiss-Axiovert 40 CFL microscope and processed using Image J software (NIH, USA).

\section{Western blot analysis}

Caspase-1 and RIP-1 levels (total and cleaved) in MWCNT treated cells were evaluated 24 hours post exposure by immune blots. Briefly, proteins were collected from scrapped HBE cells using a mixture of RIPA buffer (Thermo Scientific) and protease inhibitor cocktail (Sigma Aldrich). Proteins were quantified using micro BCA (bicinchoninic acid) assay (Thermo Scientific), separated electrophoretically on a $4-12 \%$ bis-tris polyacrylamide gel and transferred to polyvinylidene difluoride (PVDF) membrane. Membranes were blocked using 3\% BSA and 
incubated with 1:500 dilution of primary rabbit monoclonal antibodies (RIP\#3493 and casapse-1\#2225, Cell Signalling) overnight at $4^{\circ} \mathrm{C}$. Membrane was extensively washed after incubation and anti -rabbit HRP-conjugated secondary antibody (1:10,000) (Cell Signalling) was applied for 2 hours. After washing, chemiluminescent signal was developed using ECL Prime (Thermo Scientific) and detected using GBox digital imaging system (SynGene, Frederick MD). Densitometric analysis was performed using Gene-Sys densitometry software (SynGene, Frederick MD) and signal was normalized to $\alpha / \beta$ tubulin (\#2148, Cell Signalling) (1:1000).

\section{Mitochondrial membrane potential $(\Delta \Psi)$}

Mitochondrial membrane potential dynamics were evaluated by measuring $\Delta \Psi \mathrm{m}$ with mitochondrial selective probe JC-1 (Invitrogen) according to manufacturer's recommendations. JC-1 is mitochondrial selective probe which accumulates in the mitochondria in potential dependent manner and show a fluorescence emission shift from green $(\sim 529)$ to red $(\sim 590)$. Cells with damaged mitochondria show higher green fluorescence than red. After desired incubation periods, cells were stained and live cell images were taken using Zeiss-Axiovert 40 CFL microscope and processed using Image J software (NIH, USA).

\section{Lipid peroxidation}

Lipid peroxidation was estimated in MWCNT treated cells using Click-iT ${ }^{\oplus}$ Lipid Peroxidation Imaging Kit - Alexa Fluor $^{\circledR} 488$ (Molecular Probes ${ }^{\odot}$ ) according to manufacturers recommendations. Fluorescence images were taken using Zeiss-Axiovert $40 \mathrm{CFL}$ microscope and processed using Image J software (NIH, USA).

\section{Statistical analysis}

Data are presented as Mean \pm SEM from at least three independent experiments with triplicate of each condition during these repeats. Data distribution was analyzed by D'Agostino-Pearson omnibus normality test. Data were analyzed using one-way or two-way Analysis of Variance (ANOVA) followed by Tukey's post hoc test for multiple comparisons using Graphpad Prism software Version 6.0 (Graphpad Software Inc. San Diego CA). Differences were considered statistically significant at $p<0.05$ (two-tailed).

\section{Additional files}

Additional file 1: Size distribution (DLS Analyses) of nanomaterials used.

Additional file 2: TEM analysis of MWCNT uptake by HBE cells after 24 hours exposure.

Additional file 3: Kinetics of cytotoxicity in HBE cells after MWCNT exposure.
Additional file 4: LDH Release and Trypan Blue Exclusion counts for toxicity estimation. A) a dose response of $\mathrm{LDH}$ release in the cell culture supernatants after MWCNT exposure for 24 hours. LDH positive control (1:5000) dilution was incubated with nanotubes $(24 \mu \mathrm{g} / \mathrm{ml})$ for 24 hours and measured to check for interference with $\mathrm{LDH}$ in addition to using particle only controls for absorbance artifact. B) trypan blue exclusion counts. Data were analyzed by analysis of variance (ANOVA) followed by Tukey's post hoc test. Graphs show average \pm SEM of three independent experiments with triplicate of each condition, ${ }^{*} p<0.05$, ${ }^{* * *} p<0.001,{ }^{* * * *} p<0.0001$ (between media-treated control and treatments).

Additional file 5: Dose response analysis of caspase-1 (total and cleaved/active form) in HBE cells after MWCNT exposure for 24 hours. Tubulin was used as loading control.

Additional file 6: Immunocytochemistry for Cathepsin B in HBE cells after exposure to MWCNT ( $24 \mu \mathrm{g} / \mathrm{mL}$ ) for $\mathbf{2 4}$ hours. Nuclei were counter stained with Hoechst. Images are representative of 3 independent experiments done in duplicate.

Additional file 7: Time course for inflammatory cytokine production.

Additional file 8: A) Modulation of NF-KB (p65) phosphorylation, B) mitochondrial membrane potential changes and C) lipid peroxidation assessment using antioxidants (NAC and Cat Peg). Data were analyzed by analysis of variance (ANOVA) followed by Tukey's post hoc test. Graphs show average \pm SEM of three independent experiments with triplicate of each condition, ${ }^{* * *} p<0.0001$ (between media-treated control and treatments). Images are representative of 3 independent experiments done in duplicate.

Additional file 9: Modulation of cytotoxicity and inflammation after LPS pre-stimulation of HBE cells. Cells were pre-stimulated with $1 \mu \mathrm{g} / \mathrm{mL}$ LPS for 2 hours and then treated with MWCNT (12 or $24 \mu \mathrm{g} / \mathrm{mL}$ ) for 24 hours. A) cytotoxicity analysis by PI labelling followed by flow cytometery. B-D) inflammatory cytokine (IL-1 $\beta, I L-18, I L-8)$ production measured by ELISA. Data were analyzed by analysis of variance (ANOVA) followed by Tukey's post hoc test. Graphs show average \pm SEM of three independent experiments with triplicate of each condition, ${ }^{* *} p<0.01,{ }^{* * *} p<0.0001$ (between media-treated control and treatments).

Additional file 10: Effects of MWCNT treated HBE cell conditioned medium on A) cytotoxicity (PI analysis) and 2) ROS production (DHE analysis) from fibroblasts using flow cytometry. MRC-5 medium (DMEM/F12) alone was also used in parallel to know the non-specific effects of conditioned medium. Data were analyzed by analysis of variance (ANOVA) followed by Tukey's post hoc test. Graphs show average \pm SEM of three independent experiments with triplicate of each condition, ${ }^{* * *} \mathrm{p}<0.0001$ (between media-treated control and treatments).

Additional file 11: Analysis of other modalities (apoptosis and necroptosis) of cell death. A) A time course analysis for caspase 3/7 activation after MWCNT exposure using flow cytometery. Staurosporine $(10 \mu \mathrm{M})$ was used as a positive control. B) Western blot analysis for necroptosis protein RIP1. Data were analyzed by analysis of variance (ANOVA) followed by Tukey's post hoc test. Graphs show average \pm SEM of three independent experiments with triplicate of each condition, ${ }^{* * *} \mathrm{p}<0.0001$ (between media-treated control and treatments).

Additional file 12: Effect of media dispersants (BSA/DPPC) on the A) toxicity B) metabolic activity C) IL-1 $\beta$ production by HBE cells.

Additional file 13: Efficiency of NLRP3 SiRNA knockout A) real time RT-qPCR analysis B) immunostaining of HBE cells with our without NLRP3 SiRNA and with isotype control antibody. Graph shows average \pm SEM of three independent experiments with triplicate of each condition, ${ }^{* *} p<0.01$ (between control SiRNA and NLRP3 SiRNA, Students t-test). 


\section{Authors' contribution}

SH conceived the study, designed and performed experiments, analyzed data and wrote manuscript. SS, SMA, RJS, JDM and AR assisted in experimental work and read manuscript. JCB provided carbon nanotubes and characterization data, read the manuscript and provided intellectual input. SG supervised work, read the manuscript and provided intellectual input throughout the study. All authors read and approved the manuscript.

\section{Acknowledgements}

This work was supported by the Intramural Research Program of the $\mathrm{NIH}$, National Institute of Environmental Health Sciences (NIEHS). JCB was funded by NIEHS Grant R01-ES020897. The authors wish to thank Carl Bortner, Maria Sifre and Kevin Katen for assistance with flow cytometry and Connie Cummings and Deloris Sutton for assistance with TEM.

\section{Author details}

'Clinical Research Unit, National Institute of Environmental Health Sciences (NIEHS)/National Institute of Health (NIH), Research Triangle Park, Durham, NC, USA. ${ }^{2}$ Department of Biological Sciences, North Carolina State University, Raleigh, NC, USA.

Received: 28 February 2014 Accepted: 3 June 2014

Published: 10 June 2014

\section{References}

1. Schnorr JMS, Swager TM: Emerging applications of carbon nanotubes. Chem Mater 2011, 23(3):646-657.

2. Baughman RH, Zakhidov AA, de Heer WA: Carbon nanotubes-the route toward applications. Science 2002, 297(5582):787-792.

3. Huang YP, Lin IJ, Chen CC, Hsu YC, Chang CC, Lee MJ: Delivery of small interfering RNAs in human cervical cancer cells by polyethyleniminefunctionalized carbon nanotubes. Nanoscale Res Lett 2013, 8(1):267.

4. Singh R, Mehra NK, Jain V, Jain NK: Gemcitabine-loaded smart carbon nanotubes for effective targeting to cancer cells. J Drug Target 2013, 21(6):581-592

5. Kostarelos K, Bianco A, Prato M: Promises, facts and challenges for carbon nanotubes in imaging and therapeutics. Nat Nanotechnol 2009, 4(10):627-633.

6. Donaldson K, Murphy FA, Duffin R, Poland CA: Asbestos, carbon nanotubes and the pleural mesothelium: a review of the hypothesis regarding the role of long fibre retention in the parietal pleura, inflammation and mesothelioma. Part Fibre Toxicol 2010, 7:5.

7. Girtsman TA, Beamer CA, Wu N, Buford M, Holian A: IL-1R signalling is critical for regulation of multi-walled carbon nanotubes-induced acute lung inflammation in C57BI/6 mice. Nanotoxicology 2014, 8:17-27.

8. Wang P, Nie X, Wang Y, Li Y, Ge C, Zhang L, Wang L, Bai R, Chen Z, Zhao Y, Chen C: Multiwall carbon nanotubes mediate macrophage activation and promote pulmonary fibrosis through TGF-beta/smad signaling pathway. Small 2013, 9:3799-3811.

9. Li R, Wang X, Ji Z, Sun B, Zhang H, Chang CH, Lin S, Meng H, Liao YP, Wang $M$, Li Z, Hwang AA, Song TB, Xu R, Yang Y, Zink Jl, Nel AE, Xia T: Surface charge and cellular processing of covalently functionalized multiwall carbon nanotubes determine pulmonary toxicity. ACS Nano 2013, 7(3):2352-2368

10. Sager TM, Wolfarth MW, Andrew M, Hubbs A, Friend S, Chen TH, Porter DW, Wu N, Yang F, Hamilton RF, Holian A: Effect of multi-walled carbon nanotube surface modification on bioactivity in the C57BL/6 mouse model. Nanotoxicology 2014, 8:317-327.

11. Osmond-McLeod MJ, Poland CA, Murphy F, Waddington L, Morris H, Hawkins SC, Clark S, Aitken R, McCall MJ, Donaldson K: Durability and inflammogenic impact of carbon nanotubes compared with asbestos fibres. Part Fibre Toxicol 2011, 8:15.

12. Donaldson K, Murphy F, Schinwald A, Duffin R, Poland CA: Identifying the pulmonary hazard of high aspect ratio nanoparticles to enable their safety-by-design. Nanomedicine (Lond) 2011, 6(1):143-156.

13. Wang X, Xia T, Ntim SA, Ji Z, Lin S, Meng H, Chung CH, George S, Zhang H, Wang M, Li N, Yang Y, Castranova V, Mitra S, Bonner JC, Nel AE: Dispersal state of multiwalled carbon nanotubes elicits profibrogenic cellular responses that correlate with fibrogenesis biomarkers and fibrosis in the murine lung. ACS Nano 2011, 5(12):9772-9787.
14. Poland CA, Duffin R, Kinloch I, Maynard A, Wallace WA, Seaton A, Stone V, Brown S, Macnee W, Donaldson K: Carbon nanotubes introduced into the abdominal cavity of mice show asbestos-like pathogenicity in a pilot study. Nat Nanotechnol 2008, 3(7):423-428.

15. Mercer RR, Hubbs AF, Scabilloni JF, Wang L, Battelli LA, Friend S, Castranova $\mathrm{V}$, Porter DW: Pulmonary fibrotic response to aspiration of multi-walled carbon nanotubes. Part Fibre Toxicol 2011, 8:21.

16. Porter DW, Hubbs AF, Mercer RR, Wu N, Wolfarth MG, Sriram K, Leonard S, Battelli L, Schwegler-Berry D, Friend S, Andrew M, Chen BT, Tsuruoka S, Endo M, Castranova V: Mouse pulmonary dose- and time courseresponses induced by exposure to multi-walled carbon nanotubes. Toxicology 2010, 269(2-3):136-147.

17. He X, Young SH, Schwegler-Berry D, Chisholm WP, Fernback JE, Ma Q: Multiwalled carbon nanotubes induce a fibrogenic response by stimulating reactive oxygen species production, activating NF-kappaB signaling, and promoting fibroblast-to-myofibroblast transformation. Chem Res Toxicol 2011, 24(12):2237-2248.

18. Ryman-Rasmussen JP, Cesta MF, Brody AR, Shipley-Phillips JK, Everitt JI, Tewksbury EW, Moss OR, Wong BA, Dodd DE, Andersen ME, Bonner JC: Inhaled carbon nanotubes reach the subpleural tissue in mice. Nat Nanotechnol 2009, 4(11):747-751.

19. Mercer RR, Hubbs AF, Scabilloni JF, Wang L, Battelli LA, Schwegler-Berry D, Castranova V, Porter DW: Distribution and persistence of pleural penetrations by multi-walled carbon nanotubes. Part Fibre Toxicol 2010, 7:28.

20. Murphy FA, Poland CA, Duffin R, Donaldson K: Length-dependent pleural inflammation and parietal pleural responses after deposition of carbon nanotubes in the pulmonary airspaces of mice. Nanotoxicology 2013, 7:1157-1167.

21. Murphy FA, Schinwald A, Poland CA, Donaldson K: The mechanism of pleural inflammation by long carbon nanotubes: interaction of long fibres with macrophages stimulates them to amplify pro-inflammatory responses in mesothelial cells. Part Fibre Toxicol 2012, 9:8.

22. Bhattacharya K, Andon FT, El-Sayed R, Fadeel B: Mechanisms of carbon nanotube-induced toxicity: focus on pulmonary inflammation. Adv Drug Deliv Rev 2013, 65:2087-2097.

23. Patel V: Global carbon nanotubes market outlook: industry beckons. Nanotech Insights 2011, 2:31-35.

24. Postma DS, Timens W: Remodeling in asthma and chronic obstructive pulmonary disease. Proc Am Thorac Soc 2006, 3(5):434-439.

25. Krimmer DI, Burgess JK, Wooi TK, Black JL, Oliver BG: Matrix proteins from smoke-exposed fibroblasts are pro-proliferative. Am J Respir Cell Mol Biol 2012, 46(1):34-39.

26. Eickelberg O, Kohler E, Reichenberger F, Bertschin S, Woodtli T, Erne $\mathrm{P}$, Perruchoud AP, Roth M: Extracellular matrix deposition by primary human lung fibroblasts in response to TGF-beta1 and TGF-beta3. Am J Physiol 1999, 276(5 Pt 1):L814-L824.

27. Chen T, Nie H, Gao X, Yang J, Pu J, Chen Z, Cui X, Wang Y, Wang H, Jia G: Epithelial-mesenchymal transition involved in pulmonary fibrosis induced by multi-walled carbon nanotubes via TGF-beta/Smad signaling pathway. Toxicol Lett 2014, 226:50-62.

28. Schroder K, Tschopp J: The inflammasomes. Cell 2010, 140(6):821-832

29. Palomaki J, Valimaki E, Sund J, Vippola M, Clausen PA, Jensen KA, Savolainen K, Matikainen S, Alenius H: Long, needle-like carbon nanotubes and asbestos activate the NLRP3 inflammasome through a similar mechanism. ACS Nano 2011, 5(9):6861-6870.

30. Meunier E, Coste A, Olagnier D, Authier H, Lefevre L, Dardenne C, Bernad J, Beraud M, Flahaut E, Pipy B: Double-walled carbon nanotubes trigger IL-1beta release in human monocytes through Nlrp3 inflammasome activation. Nanomedicine 2012, 8(6):987-995

31. Bals R, Hiemstra PS: Innate immunity in the lung: how epithelial cells fight against respiratory pathogens. Eur Respir J 2004, 23(2):327-333.

32. Mortaz E, Masjedi MR, Allameh A, Adcock IM: Inflammasome signaling in pathogenesis of lung diseases. Curr Pharm Des 2012, 18(16):2320-2328.

33. Lambrecht BN, Hammad H: The airway epithelium in asthma. Nat Med 2012, 18(5):684-692.

34. Selman M, Pardo A: Role of epithelial cells in idiopathic pulmonary fibrosis: from innocent targets to serial killers. Proc Am Thorac Soc 2006, 3(4):364-372.

35. Peeters PM, Perkins TN, Wouters EF, Mossman BT, Reynaert NL: Silica induces NLRP3 inflammasome activation in human lung epithelial cells. Part Fibre Toxicol 2013, 10:3. 
36. Madtes DK, Elston AL, Kaback LA, Clark JG: Selective induction of tissue inhibitor of metalloproteinase-1 in bleomycin-induced pulmonary fibrosis. Am J Respir Cell Mol Biol 2001, 24(5):599-607.

37. Shahzeidi S, Jeffery PK, Laurent GJ, McAnulty RJ: Increased type I procollagen mRNA transcripts in the lungs of mice during the development of bleomycin-induced fibrosis. Eur Respir J 1994, 7(11):1938-1943.

38. Tsukui T, Ueha S, Abe J, Hashimoto S, Shichino S, Shimaoka T, Shand FH, Arakawa Y, Oshima K, Hattori M, Inagaki Y, Tomura M, Matsushima K: Qualitative rather than quantitative changes are hallmarks of fibroblasts in bleomycin-induced pulmonary fibrosis. Am J Pathol 2013, 183(3):758-773.

39. Jones PL, Jones FS: Tenascin- $C$ in development and disease: gene regulation and cell function. Matrix Biol 2000, 19(7):581-596.

40. Carey WA, Taylor GD, Dean WB, Bristow JD: Tenascin-C deficiency attenuates TGF-ss-mediated fibrosis following murine lung injury. Am J Physiol Lung Cell Mol Physiol 2010, 299(6):L785-793.

41. Amin K, Ludviksdottir D, Janson C, Nettelbladt O, Bjornsson E, Roomans GM, Boman $G$, Seveus L, Venge P: Inflammation and structural changes in the airways of patients with atopic and nonatopic asthma. BHR Group. Am J Respir Crit Care Med 2000, 162(6):2295-2301.

42. Cataldo D, Munaut C, Noel A, Frankenne F, Bartsch P, Foidart JM, Louis R: MMP-2- and MMP-9-linked gelatinolytic activity in the sputum from patients with asthma and chronic obstructive pulmonary disease. Int Arch Allergy Immunol 2000, 123(3):259-267.

43. Matsumoto S, Tanaka K: Pancreatic islet cell transplantation using non-heart-beating donors (NHBDs). J Hepatobiliary Pancreat Surg 2005, 12(3):227-230

44. Sos Poulsen S, Jacobsen NR, Labib S, Wu D, Husain M, Williams A, Bogelund JP, Andersen O, Kobler C, Molhave K, Kyjovska ZO, Saber AT, Wallin H, Yauk CL, Vogel U, Halappanavar S: Transcriptomic analysis reveals novel mechanistic insight into murine biological responses to multi-walled carbon nanotubes in lungs and cultured lung epithelial cells. PLoS One 2013, 8(11):e80452.

45. Mangum J, Bermudez E, Sar M, Everitt J: Osteopontin expression in particle-induced lung disease. Exp Lung Res 2004, 30(7):585-598.

46. Huizar I, Malur A, Midgette YA, Kukoly C, Chen P, Ke PC, Podila R, Rao AM, Wingard CJ, Dobbs L, Barna BP, Kavuru MS, Thomassen MJ: Novel murine model of chronic granulomatous lung inflammation elicited by carbon nanotubes. Am J Respir Cell Mol Biol 2011, 45(4):858-866.

47. O'Regan A: The role of osteopontin in lung disease. Cytokine Growth Factor Rev 2003, 14(6):479-488.

48. Pardo A, Gibson K, Cisneros J, Richards TJ, Yang Y, Becerril C, Yousem S, Herrera I, Ruiz V, Selman M, Kaminski N: Up-regulation and profibrotic role of osteopontin in human idiopathic pulmonary fibrosis. PLoS Med 2005, 2(9):e251.

49. Sun $B$, Wang $X$, Ji Z, Li R, Xia T: NLRP3 inflammasome activation induced by engineered nanomaterials. Small 2013, 9(9-10):1595-1607.

50. Dostert C, Petrilli V, Van Bruggen R, Steele C, Mossman BT, Tschopp J: Innate immune activation through Nalp3 inflammasome sensing of asbestos and silica. Science 2008, 320(5876):674-677.

51. Sandberg WJ, Lag M, Holme JA, Friede B, Gualtieri M, Kruszewski M, Schwarze PE, Skuland T, Refsnes M: Comparison of non-crystalline silica nanoparticles in IL-1beta release from macrophages. Part Fibre Toxicol 2012, 9:32.

52. Winter M, Beer HD, Hornung V, Kramer U, Schins RP, Forster I: Activation of the inflammasome by amorphous silica and $\mathrm{TiO} 2$ nanoparticles in murine dendritic cells. Nanotoxicology 2011, 5(3):326-340.

53. Martinon F, Petrilli V, Mayor A, Tardivel A, Tschopp J: Gout-associated uric acid crystals activate the NALP3 inflammasome. Nature 2006, 440(7081):237-241.

54. Hirota JA, Hirota SA, Warner SM, Stefanowicz D, Shaheen F, Beck PL, Macdonald JA, Hackett TL, Sin DD, Van Eeden S, Knight DA: The airway epithelium nucleotide-binding domain and leucine-rich repeat protein 3 inflammasome is activated by urban particulate matter. J Allergy Clin Immunol 2012, 129(4):1116-1125 e1116.

55. Artlett CM, Sassi-Gaha S, Rieger JL, Boesteanu AC, Feghali-Bostwick CA, Katsikis PD: The inflammasome activating caspase 1 mediates fibrosis and myofibroblast differentiation in systemic sclerosis. Arthritis Rheum 2011, 63(11):3563-3574.

56. Artlett CM: The role of the NLRP3 inflammasome in fibrosis. Open Rheumatol J 2012, 6:80-86.

57. Scrivo R, Vasile M, Bartosiewicz I, Valesini G: Inflammation as "common soil" of the multifactorial diseases. Autoimmun Rev 2011, 10(7):369-374.
58. Deschamps AM, Spinale FG: Pathways of matrix metalloproteinase induction in heart failure: bioactive molecules and transcriptional regulation. Cardiovasc Res 2006, 69(3):666-676

59. Guo H, Cai CQ, Schroeder RA, Kuo PC: Osteopontin is a negative feedback regulator of nitric oxide synthesis in murine macrophages. J Immunol 2001, 166(2):1079-1086.

60. Im H, Ammit AJ: The NLRP3 inflammasome: role in airway inflammation Clin Exp Allergy 2014, 44:160-172.

61. Reisetter AC, Stebounova LV, Baltrusaitis J, Powers L, Gupta A, Grassian VH, Monick MM: Induction of inflammasome-dependent pyroptosis by carbon black nanoparticles. J Biol Chem 2011, 286(24):21844-21852.

62. Yang EJ, Kim S, Kim JS, Choi IH: Inflammasome formation and IL-1 beta release by human blood monocytes in response to silver nanoparticles. Biomaterials 2012, 33(28):6858-6867.

63. Savage CDL-CG, Denes A, Brough D: NLRP3-inflammasome activating DAMPs stimulate an inflammatory response in glia in the absence of priming which contributes to brain inflammation after injury. Front Immunol 2012, 18(3):288

64. Kerur N, Hirano Y, Tarallo V, Fowler BJ, Bastos-Carvalho A, Yasuma T, Yasuma R, Kim Y, Hinton DR, Kirschning CJ, Gelfand BD, Ambati J: TLR-independent and P2X7-dependent signaling mediate Alu RNA-induced NLRP3 inflammasome activation in geographic atrophy. Invest Ophthalmol Vis Sci 2013, 54(12):7395-7401

65. Shi LMD, Guadarrama AG, Lenertz LY, Denlinger LC: Rhinovirus-induced $\mathrm{IL}-1 \beta$ release from bronchial epithelial cells is independent of functional P2X7. Am J Respir Cell Mol Biol 2012, 47(3):363-371.

66. Tabet L, Bussy C, Amara N, Setyan A, Grodet A, Rossi MJ, Pairon JC, Boczkowski J, Lanone S: Adverse effects of industrial multiwalled carbon nanotubes on human pulmonary cells. J Toxicol Environ Health A 2009, 72(2):60-73.

67. Warheit DB, Webb TR, Colvin VL, Reed KL, Sayes CM: Pulmonary bioassay studies with nanoscale and fine-quartz particles in rats: toxicity is not dependent upon particle size but on surface characteristics. Toxicol Sci 2007, 95(1):270-280.

68. Hussain S, Al-Nsour F, Rice AB, Marshburn J, Yingling B, Ji Z, Zink Jl, Walker NJ, Garantziotis S: Cerium dioxide nanoparticles induce apoptosis and autophagy in human peripheral blood monocytes. ACS Nano 2012, 6(7):5820-5829.

69. Armand L, Dagouassat M, Belade E, Simon-Deckers A, Le Gouvello S, Tharabat C, Duprez C, Andujar P, Pairon JC, Boczkowski J, Lanone S: Titanium dioxide nanoparticles induce matrix metalloprotease 1 in human pulmonary fibroblasts partly via an interleukin-1beta-dependent mechanism. Am J Respir Cell Mol Biol 2013, 48(3):354-363.

70. Val S, Hussain S, Boland S, Hamel R, Baeza-Squiban A, Marano F: Carbon black and titanium dioxide nanoparticles induce pro-inflammatory responses in bronchial epithelial cells: need for multiparametric evaluation due to adsorption artifacts. Inhal Toxicol 2009, 21(Suppl 1):115-122.

71. Guadagnini R, Halamoda Kenzaoui B, Cartwright L, Pojana G, Magdolenova Z, Bilanicova D, Saunders M, Juillerat L, Marcomini A, Huk A, Dusinska M, Fjellsbo LM, Marano F, Boland S: Toxicity screenings of nanomaterials: challenges due to interference with assay processes and components of classic in vitro tests. Nanotoxicology 2013. doi:10.3109/17435390.2013.829590.

72. Hussain S, Thomassen LC, Ferecatu I, Borot MC, Andreau K, Martens JA, Fleury J, Baeza-Squiban A, Marano F, Boland S: Carbon black and titanium dioxide nanoparticles elicit distinct apoptotic pathways in bronchial epithelial cells. Part Fibre Toxicol 2010, 7:10.

73. Vietti G, Ibouraadaten S, Palmai-Pallag M, Yakoub Y, Bailly C, Fenoglio I, Marbaix E, Lison D, van den Brule S: Towards predicting the lung fibrogenic activity of nanomaterials: experimental validation of an in vitro fibroblast proliferation assay. Part Fibre Toxicol 2013, 10:52.

\section{doi:10.1186/1743-8977-11-28}

Cite this article as: Hussain et al:: Inflammasome activation in airway epithelial cells after multi-walled carbon nanotube exposure mediates a profibrotic response in lung fibroblasts. Particle and Fibre Toxicology 2014 11:28 